\title{
Article \\ Spreading and Drying Dynamics of Water Drop on Hot Surface of Superwicking Ti-6Al-4V Alloy Material Fabricated by Femtosecond Laser
}

\author{
Ranran Fang ${ }^{1}$, Zekai Li ${ }^{1}$, Xianhang Zhang ${ }^{1}$, Xiaohui Zhu ${ }^{1}$, Hanlin Zhang ${ }^{1}$, Junchang Li ${ }^{1}$, Zhonglin Pan ${ }^{2}$, \\ Zhiyu Huang ${ }^{2}{ }^{-}$, Chen Yang ${ }^{2}$, Jiangen Zheng ${ }^{1}$, Wensheng Yan ${ }^{1}$, Yi Huang ${ }^{1}$, Valeriy S. Maisotsenko ${ }^{3}$ \\ and Anatoliy Y. Vorobyev ${ }^{1, *}$
}

1 School of Optoelectronic Engineering, Chongqing University of Posts and Telecommunications, 2 Chongwen Road, Nanan District, Chongqing 400065, China; fangrr@cqupt.edu.cn (R.F.); LZK_KAI@163.com (Z.L.); s190402010@stu.cqupt.edu.cn (X.Z.); zxh15111976635@163.com (X.Z.); zhl755345869@163.com (H.Z.); whaleair@163.com (J.L.); zhengjiangen@cqu.edu.cn (J.Z.); yws118@gmail.com (W.Y.); huangy@cqupt.edu.cn (Y.H.)

2 School of Science, Chongqing University of Posts and Telecommunications, 2 Chongwen Road, Nanan District, Chongqing 400065, China; pzl15185309575@163.com (Z.P.); huangzhiyu1026@hotmail.com (Z.H.); y2379202627@163.com (C.Y.)

3 M-Cycle Corporation, 1120 Delaware St. \#110, Denver, CO 80204, USA; valeriymaisotsenko@gmail.com

* Correspondence: ayv@cqupt.edu.cn

\section{check for} updates

Citation: Fang, R.; Li, Z.; Zhang, X.; Zhu, X.; Zhang, H.; Li, J.; Pan, Z.;

Huang, Z.; Yang, C.; Zheng, J.; et al. Spreading and Drying Dynamics of Water Drop on Hot Surface of Superwicking Ti-6Al-4V Alloy Material Fabricated by Femtosecond Laser. Nanomaterials 2021, 11, 899. https://doi.org/10.3390/

nano11040899

Academic Editor: Koji Sugioka

Received: 2 March 2021

Accepted: 30 March 2021

Published: 1 April 2021

Publisher's Note: MDPI stays neutral with regard to jurisdictional claims in published maps and institutional affiliations.

Copyright: (c) 2021 by the authors. Licensee MDPI, Basel, Switzerland. This article is an open access article distributed under the terms and conditions of the Creative Commons Attribution (CC BY) license (https:/ / creativecommons.org/licenses/by/ $4.0 /)$.

\begin{abstract}
A superwicking Ti-6Al-4V alloy material with a hierarchical capillary surface structure was fabricated using femtosecond laser. The basic capillary surface structure is an array of micropillars/microholes. For enhancing its capillary action, the surface of the micropillars/microholes is additionally structured by regular fine microgrooves using a technique of laser-induced periodic surface structures (LIPSS), providing an extremely strong capillary action in a temperature range between $23^{\circ} \mathrm{C}$ and $80^{\circ} \mathrm{C}$. Due to strong capillary action, a water drop quickly spreads in the wicking surface structure and forms a thin film over a large surface area, resulting in fast evaporation. The maximum water flow velocity after the acceleration stage is found to be $225-250 \mathrm{~mm} / \mathrm{s}$. In contrast to other metallic materials with surface capillarity produced by laser processing, the wicking performance of which quickly degrades with time, the wicking functionality of the material created here is long-lasting. Strong and long-lasting wicking properties make the created material suitable for a large variety of practical applications based on liquid-vapor phase change. Potential significant energy savings in air-conditioning and cooling data centers due to application of the material created here can contribute to mitigation of global warming.
\end{abstract}

Keywords: femtosecond laser processing; nanostructures; microstructures; laser-induced periodic surface structures (LIPSS); wicking materials; super-hydrophilic materials; surface capillarity; cooling of electronics; Maisotsenko cycle; global warming

\section{Introduction}

Recent trends in cooling data centers [1,2], heat dissipation in high-heat flux electronics [3], cooling supercomputers [4], spacecraft thermal management [5-7], water desalination [8-10], waste heat recovery [11-14], cooling batteries [15], energy-harvesting [16-19], aircraft anti-icing [20], and Maisotsenko cycle (M-cycle) technologies [21-25] necessitate the creation of advanced capillary materials with efficient wicking/super-hydrophilic functionality at elevated temperatures. In particular, there is a fast-growing demand for these materials in cooling high-heat flux 5G electronics and in creating the next generation of M-cycle air-conditioning systems that will consume less electric power than the traditional compressor coolers by a factor of 5-8 [21,26-29]. In view of the fact that the air-conditioning of buildings and cooling data centers consume about $15 \%$ of global electricity generation, 
the energy efficiency in these sectors is an important factor for mitigation of global warming through reduction of air pollution associated with electricity generation.

A typical wicking medium currently used in heat pipes for cooling electronics is a porous material (mesh or sintered powder), performance of which degrades at high heat fluxes because of insufficient liquid transport and large thickness of the wicking medium $(>0.5 \mathrm{~mm})$ that limit the heat transfer [30-32]. Hierarchical wicking materials based on the surface capillary effect offer significantly enhanced cooling performance due to a high velocity of liquid transport, small thickness $(<100 \mu \mathrm{m})$, and efficient evaporative functionality [33-38]. Prior studies also show that as compared with wire meshes, sintered powders, and microgroove structures, the micropillar arrays [39,40], especially hierarchical ones [41,42], provide superior heat transfer performance due to their good wicking, large surface area enhancement, and high evaporation rate owing to a large thin-film evaporation area $[41,43,44]$. Previously, surface nano/microstructuring of materials $[34,45]$ using direct laser ablation [46-50] has been successfully applied to fabrication of superwicking silicon [36,51], metals [10,14,33,37,52], glasses [53,54], and polymers [38] by producing an array of parallel microgrooves on a surface of a material. It has been demonstrated that this open capillary surface structure provides a strong capillary force capable of unidirectional transporting of water for a long distance, even against the force of gravity. In contrast to previously studied microgroove structures produced by femtosecond laser processing, we investigate a hierarchical micropillar/microhole array structure. To enhance capillary action, the surface of micropillars/microholes is structured with regular fine microgrooves using a technique of laser-induced periodic surface structures $[34,55,56]$. In our work, the capillary structure is produced on a surface of a Ti-6Al-4V alloy sample. To characterize wicking functionality of the created material, we investigate water spreading distance $z$ as a function of time $t$ in a temperature range between 23 and $80^{\circ} \mathrm{C}$ using high-speed video imaging. Our study shows that in the initial stage of the capillary flow, the water spreading distance achieves a very large value of about $9-11 \mathrm{~mm}$ at $t=100 \mathrm{~ms}$ and the maximum spreading velocity reaches about $225-250 \mathrm{~mm} / \mathrm{s}$ in the studied temperature range, demonstrating excellent wicking performance at elevated temperatures.

Metals are preferable wicking materials for heat/mass exchangers due to their high inherent thermal conductance. However, previous studies have revealed that the creation of long-term stable metallic wicks encounters a problem of quick degradation of their capillary functionality caused by contamination via adsorption of hydrocarbons from the ambient air [57]. For example, femtosecond laser-treated metals are super-hydrophilic/superwicking immediately after laser processing, but they quickly become superhydrophobic after exposing to laboratory air from several days to several months $[45,58]$. Here, we find that in contrast to pure $\mathrm{Ti}$ [58] and other metals [45], the super-hydrophilic/wicking properties of titanium alloy (Ti-6Al-4V) degrade very slowly after femtosecond laser processing, making the created material suitable for practical applications. Due to the long-term stability and excellent wicking performance in a wide temperature range, the created material can significantly enhance the efficiency of commercially available M-cycle air-conditioners, where thick porous wicking cellulose pads are currently used. In particular, the application of the wicking material created here can provide significant energy savings in air-conditioning of buildings [59] and cooling data centers [60].

\section{Experimental: Fabrication and Characterization}

In our study, we use Ti-6Al-4V alloy plates purchased from Goodfellow. Before laser processing, the samples were wiped with alcohol and then cleaned in an ultrasonic cleaner with distilled water at $40{ }^{\circ} \mathrm{C}$ to rinse away remaining contaminants. To fabricate an array of LIPSS-structured micropillars/microholes, we use a femtosecond laser processing setup, as shown Figure 1a. Our femtosecond laser system (Astrella, Coherent Inc., Santa Clara, CA, USA) generates $86 \mathrm{fs}$ pulses with energy of $7.13 \mathrm{~mJ} /$ pulse at a maximum repetition rate of $1 \mathrm{kHz}$, with a central wavelength of $800 \mathrm{~nm}$. A lens with a focal distance of $200 \mathrm{~mm}$ focuses the laser beam onto the Ti-6Al-4V sample mounted 
on a computer-controlled XYZ translation stage. To vary the laser power, a half-wave plate and polarizing beam-splitter cube are used. Measurements of the laser power are carried out using a non-polarizing beam-splitter and power meter. To produce the array of micropillars/microholes, we first fabricate an array of parallel microgrooves using a raster scanning of the sample across the laser beam. Then, we produce the second array of parallel microgrooves superimposed orthogonally onto the first one, resulting in an array of LIPSS-textured micropillars/microholes [56]. By varying laser fluence, step between scanning lines, scanning speed, and pulse repetition rate, we find laser processing parameters for producing a highly efficient wicking micropillar/microhole array structure. In this work, we fabricate a wicking array of LIPSS-structured micropillars/microholes at normal incidence of the laser beam using laser fluence of $5.1 \mathrm{~J} / \mathrm{cm}^{2}$, laser spot diameter of $120 \mu \mathrm{m}$, step between scanning lines of $100 \mu \mathrm{m}$, pulse repetition rate of $1000 \mathrm{~Hz}$, and scanning speed of $0.9 \mathrm{~mm} / \mathrm{s}$. Laser processing of Ti-6Al-4V alloy plates is carried out in air of atmospheric pressure at the temperature of $23{ }^{\circ} \mathrm{C}$ and relative humidity of $50 \%$. The dimensions of the laser-textured surface area are $14 \times 25 \mathrm{~mm}$. The structural features of the produced wicking micropillar/microhole array are examined using a scanning electron microscope (SEM) MIRA 3 from Tescan (Brno, Czech Republic) and three-dimensional (3D) laser scanning microscope VK-X1100 from Keyence. The elemental composition of both treated and untreated sample surfaces is studied by energy dispersive X-ray spectroscopy (EDS) using a Brucker XFlash 6/30 detector (Karlsruhe, Germany). The wetting properties of the treated and untreated sample surfaces are characterized by measuring water contact angle, $\theta_{\mathrm{CA}}$, using an OSA 200 system (Ningbo NB Scientific Instruments, Ningbo, China) equipped with an accessory for measuring $\theta_{\mathrm{CA}}$ as a function of temperature, $T$.

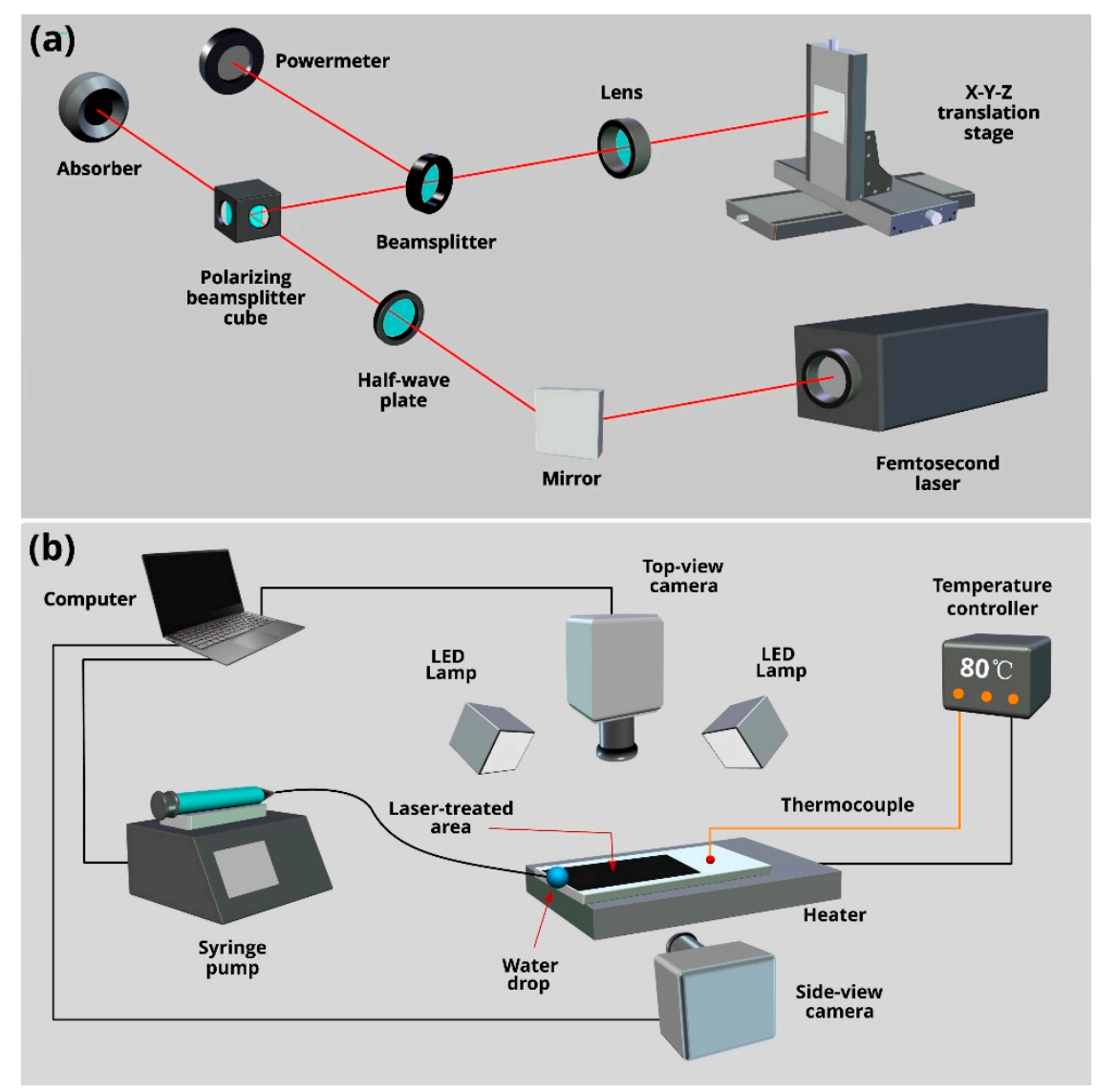

Figure 1. (a) Femtosecond laser setup for producing an array LIPSS-structured micropillars/microholes. (b) Experimental setup for high-speed video capturing of water spreading on the wicking surface at various temperatures. 
The wicking properties of the produced structure are studied by video capturing the capillary flow dynamics of de-ionized water on a horizontally positioned sample using the experimental setup presented in Figure $1 \mathrm{~b}$. The studied sample is attached onto a heater. To regulate the sample surface temperature, we use a temperature controller (TCN4S from Autonics, Busan, South Korea) and thermocouple (5TC-TT-K-30-36 from Omega, Norwalk, CT, USA) mounted on the untreated sample surface. In our study, water is supplied to the capillary structure from a pendant $5 \mu \mathrm{L}$ drop. To produce the pendant drop, we use a syringe pump Elite 11 from Harward Apparatus Inc. (Holliston, MA, USA). The water capillary flow dynamics are studied using a high-speed VEO 710L Phantom camera at a speed of 1000 frames per second (fps). The water flow behavior is investigated at sample surface temperature $T=23,40,60$, and $80^{\circ} \mathrm{C}$, relative humidity of the ambient air of $50 \%$, and ambient air temperature of $23^{\circ} \mathrm{C}$. Due to evaporation, the temperature of a pendant water droplet before its relocation onto the sample can be lower than the room temperature $\left(23^{\circ} \mathrm{C}\right)$. To measure the water droplet temperature, we use a miniature thermocouple placed inside the water droplet $[61,62]$, and the water droplet temperature is measured to be $20.8^{\circ} \mathrm{C}$. From video recording, we find the dependence of water spreading distance, $z$, as a function of time, $t$. Using $z(t)$ data, we also derive the water spreading velocity, $v$, as a numerical derivative $\Delta z / \Delta t$, where $\Delta z$ is the difference of spreading distance between two consecutive video frames and $\Delta t=10^{-3} \mathrm{~s}$. In our study, we shot three videos for each studied temperature. After processing these videos, the most characteristic one was selected for presenting in this paper. In our study, we also investigated the water film thickness dynamics using a side-view camera (see Figure 1b). For side-view imaging, we used a high-speed V2012 Phantom camera.

\section{Results and Discussion}

The commonly termed 'laser technique for producing micropillars' [56] produces both micropillars and microholes formed at intersections of the orthogonal scanning laser beams, thus giving rise to a hybrid structure of micropillars and microholes, where the micropillar bottom is taken as a base level. The structural features of the fabricated array of LIPSSstructured micropillars/microholes are shown in Figure $2 \mathrm{a}-\mathrm{f}$. The surface of micropillars and microholes is textured with both LIPSS and random fine nano/micro-structures of various shapes and dimensions (see Figure 2b-d). A 3D optical image of the array of micropillars/microholes is demonstrated in Figure 2e. The period and averaged height of the micropillars measured by 3D laser scanning microscope are 100 and $52 \mu \mathrm{m}$, respectively (see Figure 2f). The period and averaged depth of the microholes are 100 and $41 \mu \mathrm{m}$, respectively. The dimensions of the LIPSS and fine random nano/microstructures are in a range between about $50 \mathrm{~nm}$ and $10 \mu \mathrm{m}$ (Figure $2 \mathrm{~b}-\mathrm{d}$ ). The presence of LIPSS that partially covers the micropillar/microhole walls is an important structural feature. These periodic fine microgrooves enhance the overall capillary action of the fabricated wicking material through spreading water on the micropillar/microhole walls. As seen in Figure 2c, their period and width are about 1-3 and 0.5-1.5 $\mu \mathrm{m}$, respectively. These periodic structures are a type of LIPSS produced by femtosecond laser pulses in multi-pulse ablation $[34,55,63]$. At a linearly polarized laser light, the LIPSS period, $d$, on a metal in an ambient dielectric medium reads [34]:

$$
d=\lambda_{\text {las }} /(\operatorname{Re}[\eta] \mp \sin \theta) \text { with } \mathbf{g} \| \mathbf{E}
$$

where $\lambda_{\text {las }}$ is the wavelength of incident laser light, $\theta$ is the angle of laser beam incidence, $\eta=\left[\varepsilon_{d} \varepsilon_{\text {metal }} /\left(\varepsilon_{d}+\varepsilon_{\text {metal }}\right)\right]^{1 / 2}$ is the effective refractive index of the dielectric-metal interface for surface plasmons, $\varepsilon_{d}$ is the dielectric function of the ambient dielectric medium, $\varepsilon_{\text {metal }}$ is the dielectric function of the metal, $\operatorname{Re}[\eta]$ is the real part of $\eta, \mathbf{g}$ is the grating vector of LIPSS, and $\mathbf{E}$ is the tangential component of electrical field vector of the incident laser beam. Typically, $\eta \approx 1$ for air-metal interfaces when a metal surface is smooth [63-65]. Multi-pulse femtosecond ablation at low laser fluences gives rise to the formation of surface nanostructures that cause $\eta$ to increase [63-65]. For example, $\eta \approx 1.3$ has been reported for LIPSS formation on Ti [64]. The increase in $\eta$ results in LIPSS with a period smaller 
than the laser wavelength at $\theta \approx 0$. However, the increase in $\theta$ causes the LIPSS period to increase, giving rise to the LIPSS with $d>\lambda_{\text {las }}$. The LIPSSs with the period larger than the laser wavelength have been previously studied in References [65,66]. It is known that LIPSS are produced by multi-pulse ablation of metals at laser fluence slightly above the damage threshold of a metal $[34,55,63,65]$. In the course of the micropillars/microholes fabrication, the laser-irradiated surface area significantly increases due to formation of surface structures, resulting in a reduction of laser fluence and creating conditions for LIPSS formation. Another factor that promotes LIPSS formation is a lower laser fluence on the laser beam periphery. Formation of the micropillars/microholes also causes the incidence angle to increase, resulting in increasing $d$. Here, we use these effects for producing LIPSS on the micropillar/microhole walls by a proper choice of laser processing parameters. An important feature of this approach is that this hierarchical capillary structure is produced by a one-step fabrication process. At the incidence angle of the laser beam between $30^{\circ}$ and $80^{\circ}$, the LIPSS period for metals is typically in a range of $1-4 \mu \mathrm{m}$ [65] that agrees with the range of $d$ for the fine periodic microgrooves observed on the micropillar/microhole walls in our study. Previously, it has been shown that the surfaces of metals and Ti-6Al-4V alloy undergo a significant femtosecond laser-induced oxidation [67-69]. Therefore, after laser processing of the sample, we performed an EDS examination of the elemental composition of the laser-treated surface. This study shows a significant increase in the oxygen amount caused by femtosecond laser-induced oxidation, as seen in Figure $2 g$, $h$. It is known that $\mathrm{TiO}_{2}$ oxide has very good hydrophilic properties [57], therefore its formation caused by laser processing can be beneficial to super-hydrophilic/wicking properties of our sample.

The flow of a liquid in a capillary medium undergoes a sequence of regimes, including acceleration $\left(z \propto t^{2}\right)$ [70-72], inertial $(z \propto t)$ [70-75], visco-inertial [36,76], classic Washburn's regime $\left(z \propto t^{1 / 2}\right)$ [77], and final stages [78]. In contrast to many previous works focused on the classic Washburn regime and other capillary flow stages occurring on the sub-second (0.1-1 s) and second (1-100 s) time scales [78-95], our study mainly focuses on the early capillary flow regimes on the millisecond time scale between 0 and $100 \mathrm{~ms}$, understanding of which has recently become an important issue in fast remediation of dry-out spots in cooling high-heat flux electronics of 4G/5G telecom networks [96,97], Maisotsenko cycle (M-cycle) heat/mass exchangers [98-101], and miniaturization of microfluidic devices [102], where the classic Washburn regime and later capillary flow regimes do not occur because of the short length of capillary channels. The previous studies on the initial flow regimes mainly relate to the inertial regime in capillary tubes with a smooth surface, which are the simplest capillary systems [70,73-75]. Our capillary system has a high hierarchical structural complexity. Furthermore, due to water supply from a pendant drop, the forces driving the liquid are more complicated and include the capillary pressure due to surface structure, Laplace pressure from the curvature of the drop remaining between the sample edge and needle, Laplace pressure from the curvature of the drop located on the sample, and gravitational force of the drop on the sample surface $[36,103,104]$. Therefore, the inertial regime of water behavior in our capillary system may differ from that in the capillary tubes. As an example, the inertial regime is not observed in porous capillary media [74]. 

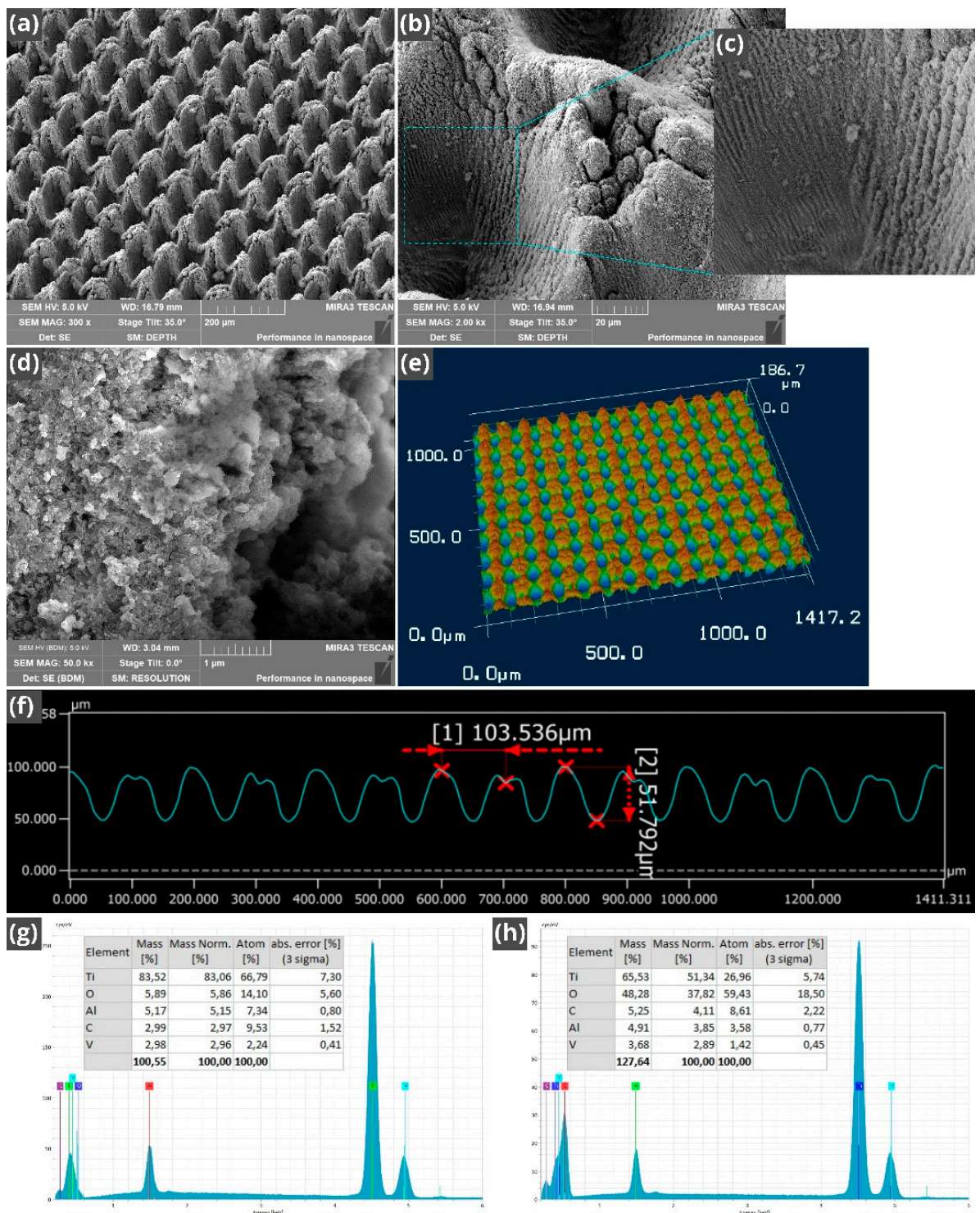

Figure 2. (a) Scanning electron microscope (SEM) image of the array of micropillars/microholes produced by femtosecond laser. (b) SEM image of a LIPSS-structured micropillar/microhole. (c) Magnified SEM image of LIPSS produced on micropillar/microhole walls. (d) SEM image of nanostructural features on the micropillar top. (e) Three-dimensional (3D) optical image of the array of micropillars/microholes. (f) Profile of the micropillars. (g) Elemental composition of the sample surface before laser processing. (h) Elemental composition of the sample surface after laser processing.

Figure 3a shows the overall plot of water spreading distance as a function of time at the sample temperature of $23^{\circ} \mathrm{C}$. It is seen that the capillary flow of water in the created material is very fast, and spreading distance reaches $25 \mathrm{~mm}$ in $2450 \mathrm{~ms}$. Figure $3 \mathrm{~b}$ presents the plot of spreading distance in the initial stages of water spreading in the time domain $0<t<100 \mathrm{~ms}$, where one can see that the spreading distance achieves large values of about 6 and $11 \mathrm{~mm}$ at 45 and $100 \mathrm{~ms}$ respectively, demonstrating strong capillary action of the created material. The plot of capillary flow velocity as a function of time shown in Figure $3 c$ reveals an acceleration stage between 0 and $4 \mathrm{~ms}$, where the velocity increases from 0 to about $250 \mathrm{~mm} / \mathrm{s}$. Snapshot b1 in Figure 3b demonstrates water spreading in the end of the acceleration stage. As seen in Snapshot b2, about a half of the water drop is relocated from the needle to the sample at $t=18 \mathrm{~ms}$. Snapshot b3 demonstrates that water relocation is almost completed at $t=48 \mathrm{~ms}$. After the acceleration stage, in the time domain between 4 and $62 \mathrm{~ms}$ (see Figure $3 \mathrm{~b}$ ), the spreading distance exhibits quasilinear flow stage $(z \propto t)$ 
composed of three linear substages indicated by dashed lines. This water flow behavior can be explained by time-dependent contributions of the above-mentioned forces driving the liquid [36]. The time domains of the linear substages are 5-18, 20-48, and 51-62 ms. These time domains correlate with water drop spreading and its shape changes affecting the water driving forces, as seen in Snapshots b1-b4 and in Figure 3e, with its associated Snapshots e1-e3 that demonstrate dynamics of the water drop profile on the sample. The plot of the spreading velocity as a function of time presented in Figure $3 \mathrm{c}$ shows significant velocity fluctuations that are explained by an uncertainty in velocity derivation and pinning/depinning effects $[36,38,105]$. The average velocity in the quasilinear regime $(4<t<62 \mathrm{~ms}$ ) is found to be $142 \mathrm{~mm} / \mathrm{s}$. In the time domain $63<t<200 \mathrm{~ms}$, the spreading velocity quickly decreases, reaching a value of about $20 \mathrm{~mm} / \mathrm{s}$ at $t=200 \mathrm{~ms}$. Snapshot $\mathrm{c} 1$ demonstrates water spreading in this time domain. At $t>200 \mathrm{~ms}$, the velocity decreases slowly with smaller fluctuations (see Figure $3 d$ and its insets i1, i2). It is seen from Snaphots $\mathrm{d} 1-\mathrm{d} 5$ that at $t>200 \mathrm{~ms}$, the spreading water takes the shape of a thin film spread over a large surface area, indicating a potentially good evaporative functionality of the created material that is useful for applications based on liquid-vapor phase change. We also investigated the dynamics of water film profile using side-view video imaging of water spreading. We found that the water film thickness, $h$, achieves a maximum value at a distance of about $4 \mathrm{~mm}$ from the sample edge, and this position of maximum $h$ almost does not change with time. The plot of the maximum $h$ as a function of time at $z=4 \mathrm{~mm}$ is shown in Figure 3e. As seen in the inset of Figure 3e, the water spreading front reaches $z=4 \mathrm{~mm}$ at $t=28 \mathrm{~ms}$, followed by a quick increase of the water film thickness that achieves a maximum value of $0.66 \mathrm{~mm}$ at $t=36 \mathrm{~ms}$. Then, the water film thickness rapidly reduces to about $0.3 \mathrm{~mm}$ at $t=55 \mathrm{~ms}$, indicating that the contributions to water flow of both Laplace pressure from the curvature of the drop located on the sample and gravitational force of this drop occur mainly in the time domain of the quasilinear inertial regime. At $t>55 \mathrm{~ms}$, the water film thickness decreases slowly, and its value becomes 200, 100, and $50 \mu \mathrm{m}$ at 420, 1100, and $1700 \mathrm{~ms}$ respectively, providing favorable conditions for efficient evaporation.

The water spreading dynamics at 40 and $60{ }^{\circ} \mathrm{C}$ are presented in Figures 4 and 5, respectively. Overall, the water behavior at $40{ }^{\circ} \mathrm{C}$ is similar to that at $23{ }^{\circ} \mathrm{C}$, as seen from a comparison of Figure $4 \mathrm{a}$ with Figure $3 \mathrm{a}$. In the initial stages, the $z(t)$ plots at these temperatures are actually the same within the measurement uncertainty (see the inset in Figure $4 \mathrm{a}$ and compare Figure $4 \mathrm{~b}$ with Figure $3 \mathrm{~b}$ ). Figure $4 \mathrm{c}$ shows that the acceleration stage takes place at $0<t<7 \mathrm{~ms}$, resulting in a maximum velocity of about $250 \mathrm{~mm} / \mathrm{s}$. Similar to the water spreading at $23{ }^{\circ} \mathrm{C}$, the spreading dynamics at $40{ }^{\circ} \mathrm{C}$ after the acceleration regime can also be characterized as a quasilinear regime composed of three linear substages, namely at $7<t<23 \mathrm{~ms}, 25<t<33 \mathrm{~ms}$, and $35<t<62 \mathrm{~ms}$, as shown by dotted lines in Figure $4 \mathrm{~b}$. Snapshots b1-b4 demonstrate the water spreading dynamics in this quasilinear regime. The $v(t)$ dependence in the time domain $0<t<100 \mathrm{~ms}$ is presented in Figure 4c. This dependence is similar to that at $23^{\circ} \mathrm{C}$, as can be seen from the comparison of Figure $4 \mathrm{c}$ with Figure 3c. The average velocity in the quasilinear regime $(7<t<62 \mathrm{~ms})$ found from the data in Figure $4 \mathrm{c}$ is $144 \mathrm{~mm} / \mathrm{s}$, which is the same as at $23{ }^{\circ} \mathrm{C}$ within the experimental uncertainty. As seen in Figure $4 \mathrm{a}$, the $z(t)$ curves at 23 and $40^{\circ} \mathrm{C}$ begin to divert at about $600 \mathrm{~ms}$, revealing somewhat smaller spreading distance at $40{ }^{\circ} \mathrm{C}$ that can be explained by a higher evaporation rate with increasing temperature. Figure $4 \mathrm{~d}$ and its insets i1 and i2 present both the overall $v(t)$ dependence and detailed $v(t)$ dependences at $t>100 \mathrm{~ms}$, where it is seen that the velocity behavior is similar to that at $23^{\circ} \mathrm{C}$. Snapshots $\mathrm{d} 1-\mathrm{d} 5$ associated with the $v(t)$ dependence in Figure $4 \mathrm{~d}$ demonstrate water spreading dynamics at $t>328 \mathrm{~ms}$. The plot of the water film thickness in Figure $4 \mathrm{e}$ also exhibits a similar behavior as at $23^{\circ} \mathrm{C}$. Thus, the presented experimental data show that the increase in temperature from 23 to $40{ }^{\circ} \mathrm{C}$ does not essentially affect the capillary water flow on the material created here. 

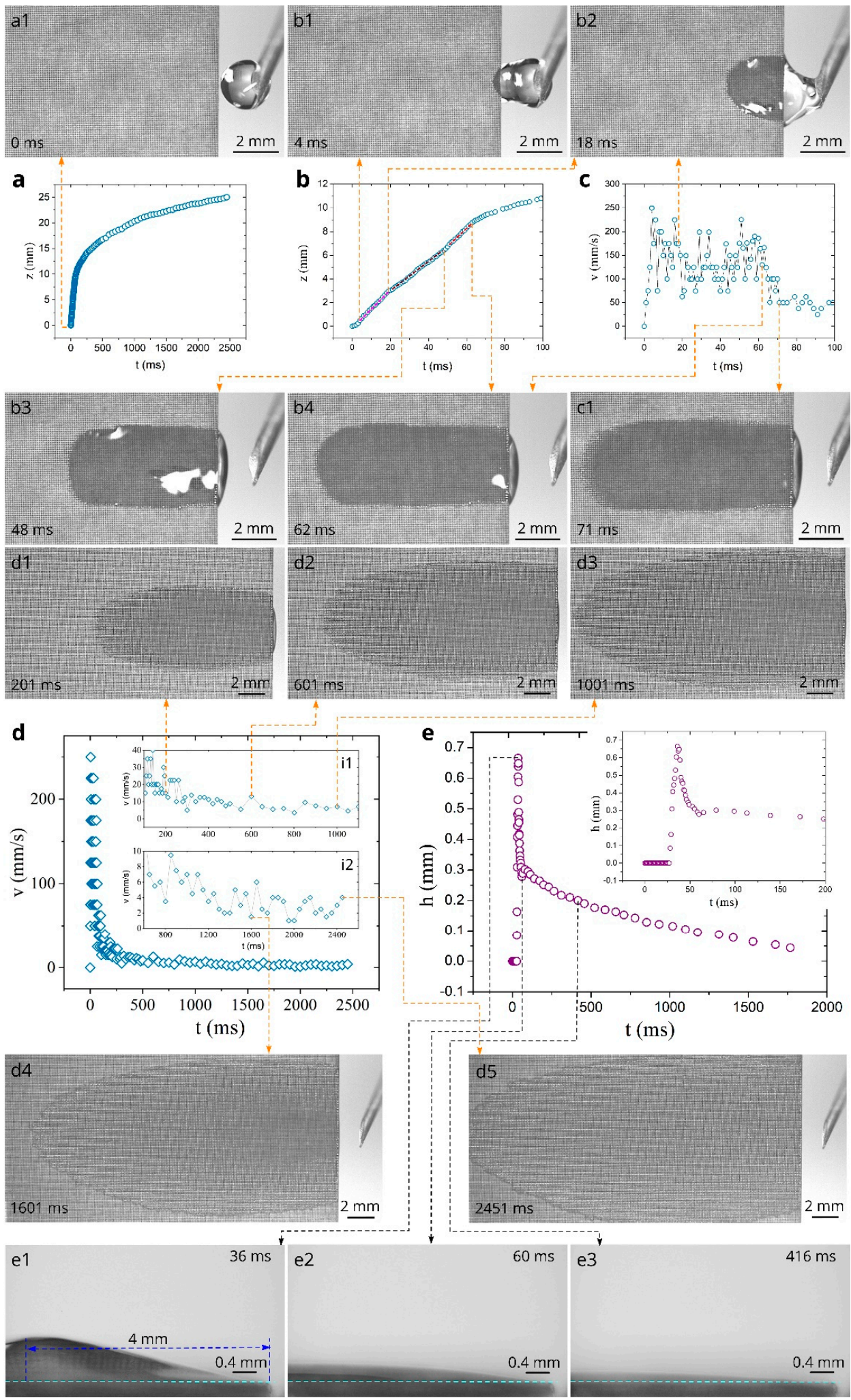

$416 \mathrm{~ms}$

Figure 3. Dependences $z(t), v(t)$, and $h(t)$ at $23^{\circ} \mathrm{C}$ and snapshots of water spreading (experiment was performed 72 days after laser processing of the sample). (a) The overall plot of the spreading distance as a function of time. (b) Detailed plot of spreading distance as a function of time between 0 and $100 \mathrm{~ms}$. The dashed lines show three $z \propto t$ substages. (c) Plot of the velocity as a function of time between 0 and $100 \mathrm{~ms}$. (d) The overall plot of the velocity as a function of time. (e) Plot of water film thickness as a function of time at $z=4 \mathrm{~mm}$. 

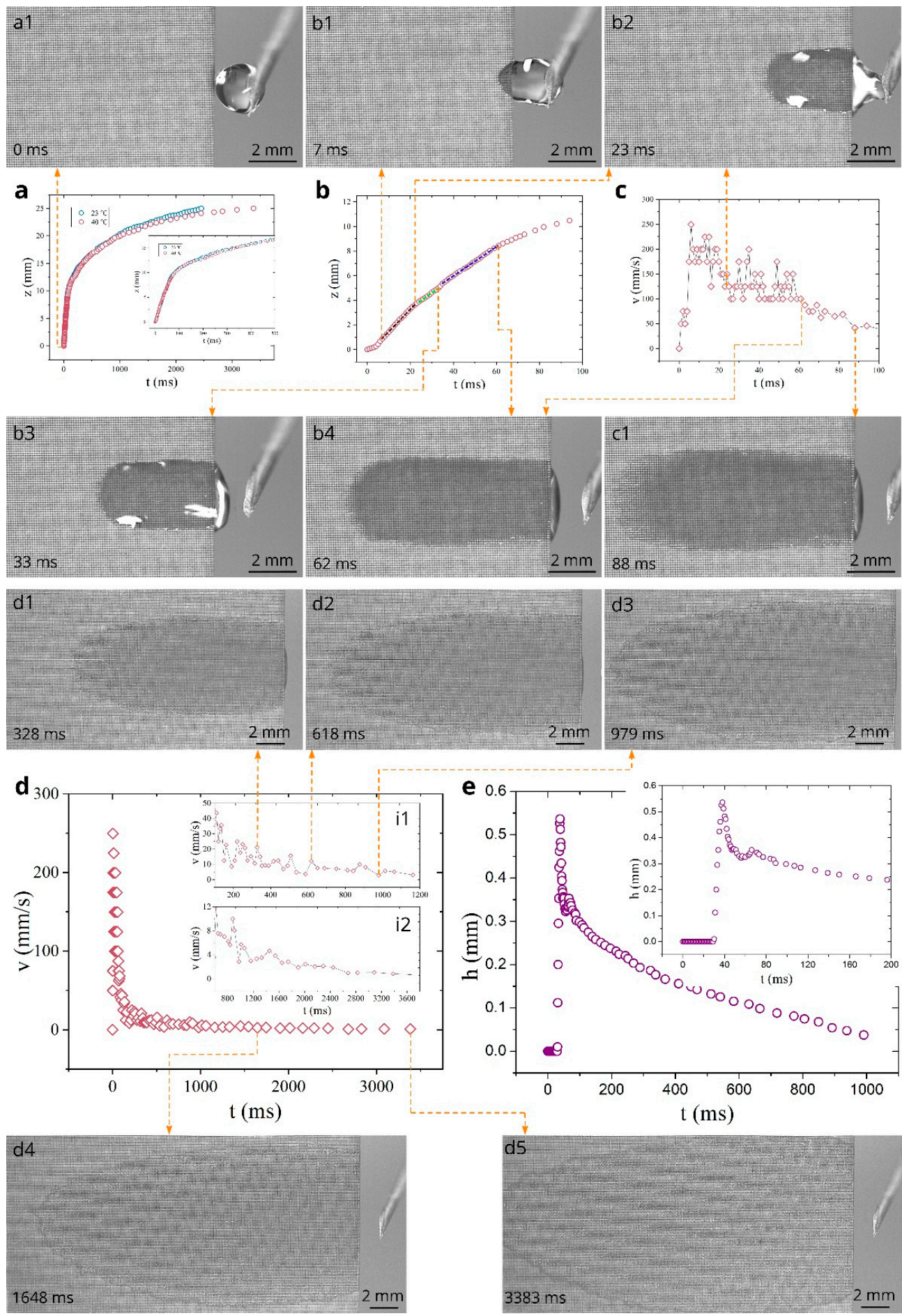

Figure 4. Dependences $z(t), v(t)$, and $h(t)$ at $40{ }^{\circ} \mathrm{C}$ and snapshots of water spreading (experiment was performed 74 days after laser processing of the sample). (a) The overall plot of the spreading distance as a function of time and its comparison with that at $23^{\circ} \mathrm{C}$. (b) Detailed $z(t)$ plot between 0 and $100 \mathrm{~ms}$. The dashed lines show three $z \propto t$ substages. (c) Plot of the velocity as a function of time between 0 and $100 \mathrm{~ms}$. (d) The overall plot of the velocity as a function of time. (e) Plot of water film thickness as a function of time at $z=4 \mathrm{~mm}$. 

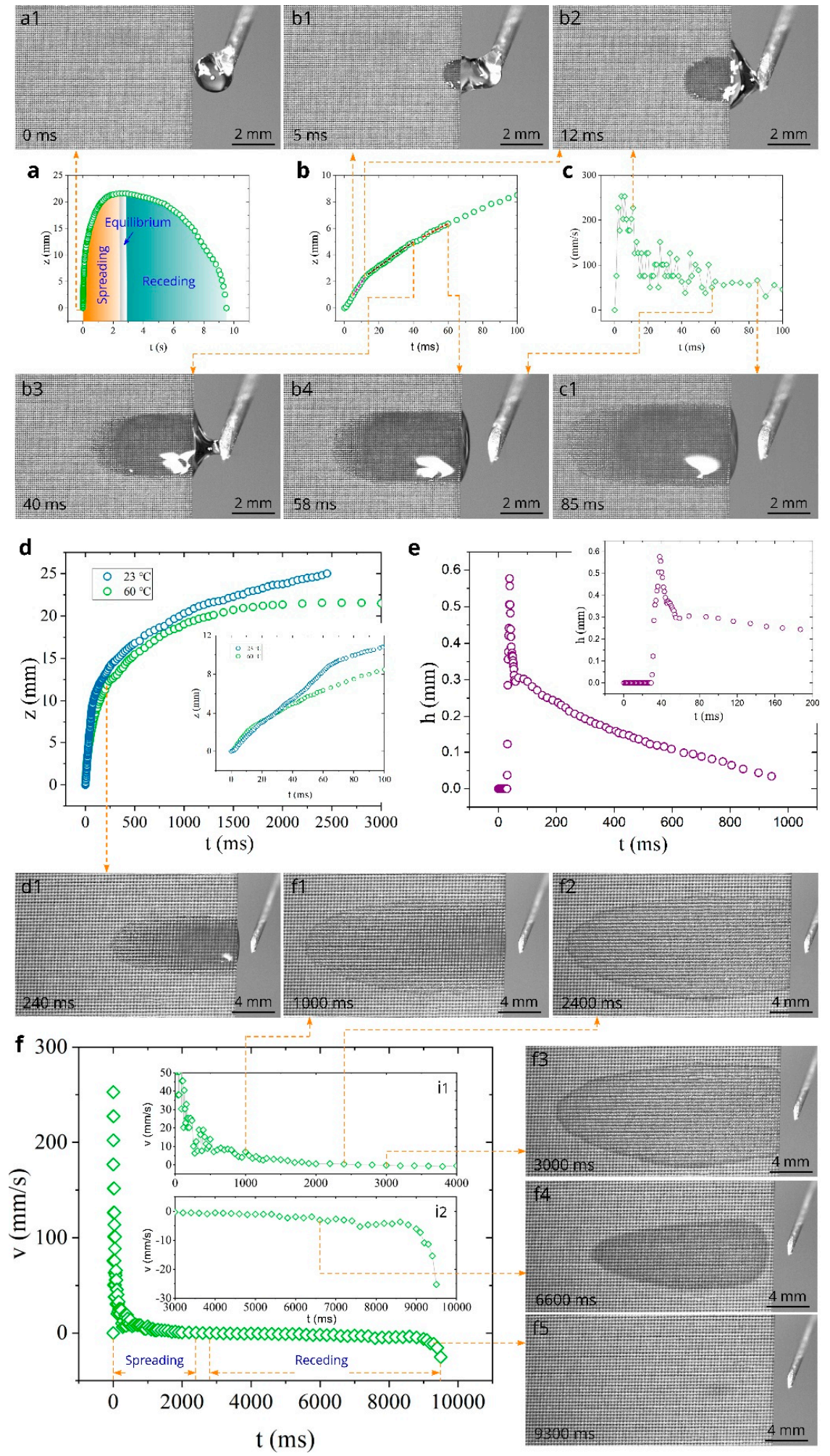

Figure 5. The $z(t), v(t)$, and $h(t)$ dependences and snapshots of water spreading and receding at $60{ }^{\circ} \mathrm{C}$ (experiment was performed 75 days after laser processing of the sample). (a) The overall plot of the spreading distance as a function of time. (b) Detailed $z(t)$ plot between 0 and $100 \mathrm{~ms}$. The dashed lines show three $z \propto t$ substages. (c) Detailed plot of the spreading velocity as a function of time between 0 and $100 \mathrm{~ms}$. (d) The comparison of $z(t)$ dependences at 23 and $60{ }^{\circ} \mathrm{C}$. (e) Plot of water film thickness as a function of time at $z=4 \mathrm{~mm}$. (f) The overall plot of spreading and receding velocities as a function of time. 
Figure 5 shows both water spreading and receding (drying) dynamics at $60^{\circ} \mathrm{C}$. As seen in Figure 5a, the spreading distance achieves its maximum value of $21.5 \mathrm{~mm}$ at $2400 \mathrm{~ms}$. This value is smaller than that at $23{ }^{\circ} \mathrm{C}(24.8 \mathrm{~mm})$ and $40{ }^{\circ} \mathrm{C}(24.0 \mathrm{~mm})$, indicating a noticeable effect of evaporation on the spreading distance. In the time domain $2400<t<2800 \mathrm{~ms}$, the water-front actually does not move, revealing an equilibrium between the capillary and evaporation effects on water spreading. After the equilibrium stage, the water-front begins to recede with an increasing velocity, resulting in complete drying of the water film. The time domains of spreading, equilibrium, and receding stages of water behavior are indicated in Figure 5 a. Figure 5 b presents the $z(t)$ dependence in the initial spreading stage between 0 and $100 \mathrm{~ms}$, where three $z \propto t$ substages are marked with dashed lines. Snapshots b1-b4 demonstrate the water behavior in these substages. The velocity of capillary spreading in the initial time domain between 0 and $100 \mathrm{~ms}$ is shown in Figure $5 \mathrm{c}$. It is seen that the water flow velocity remains to be high at $60{ }^{\circ} \mathrm{C}$, achieving a maximum value of about $250 \mathrm{~mm} / \mathrm{s}$. The average velocity in the quasilinear regime $(5<t<58 \mathrm{~ms})$ is found to be $109 \mathrm{~mm} / \mathrm{s}$, which is smaller than that at 23 and $40{ }^{\circ} \mathrm{C}$. Snapshots $\mathrm{c} 1, \mathrm{~d} 1$, and $\mathrm{f} 1$ show the water film behavior after the quasilinear stage at 85, 240, and $1000 \mathrm{ms,}$ respectively. Snapshot $\mathrm{f} 2$ shows the water film in the beginning of the equilibrium regime. The temperature effect on the water spreading behavior is demonstrated by a comparison of the spreading distances at 23 and $60{ }^{\circ} \mathrm{C}$ in Figure $5 \mathrm{~d}$, where the inset shows that the spreading distance at $60{ }^{\circ} \mathrm{C}$ becomes smaller already at about $30 \mathrm{~ms}$. As seen in Figure 5e, the $h(t)$ dependence does not undergo significant changes with increasing temperature to $60{ }^{\circ} \mathrm{C}$. Figure $5 \mathrm{f}$ and its insets (i1 and i2) demonstrate the plots of both spreading and receding velocities in the entire lifetime of the water film on the sample surface. The receding regime begins at $2800 \mathrm{~ms}$. Initially, the receding velocity increases slowly (see insets i1 and i2), achieving a value of $4.7 \mathrm{~mm} / \mathrm{s}$ at $8800 \mathrm{~ms}$. As seen in the inset i2, at $t>8800 \mathrm{~ms}$, the receding velocity quickly increases and achieves a value of $25.3 \mathrm{~mm} / \mathrm{s}$ at the end of the drying process. Snapshots $\mathrm{f} 3, \mathrm{f} 4$, and $\mathrm{f} 5$ show the water film drying dynamics. It is seen in Snapshot $\mathrm{f} 5$ that the evaporation of the water film comes to an end at $z \approx 4 \mathrm{~mm}$, where the maximum water film thickness is observed.

The data on water spreading and receding (drying) behaviors at $80^{\circ} \mathrm{C}$ are presented in Figure 6. The overall $z(t)$ dependence is shown in Figure 6a, where the time domains of spreading, equilibrium, and receding regimes are indicated. It is seen that the maximum spreading distance is observed to be $18.7 \mathrm{~mm}$ in the equilibrium stage between 1185 and $1385 \mathrm{~ms}$, indicating a significant effect of evaporation on the maximum spreading distance. The detailed $z(t)$ dependence in the time domain between 0 and $100 \mathrm{~ms}$ is demonstrated in Figure $6 \mathrm{~b}$, where three $z \propto t$ substages are marked with dashed lines. Snapshots b1-b4 associated with these substages show the water behavior in these linear substages. The $v(t)$ plot in the time domain between 0 and $100 \mathrm{~ms}$ (Figure 6c) shows that the maximum capillary flow velocity remains high (about $225 \mathrm{~mm} / \mathrm{s}$ ). The average velocity in the quasilinear regime $(6<t<61 \mathrm{~ms})$ also remains high $(108 \mathrm{~mm} / \mathrm{s})$, demonstrating excellent wicking properties at high temperatures. Snapshots $\mathrm{c} 1$ and $\mathrm{d} 1$ show the water film behavior in the spreading regime after the quasilinear stage. The temperature effect on the water spreading is clearly seen in Figure $6 \mathrm{~d}$, where a comparison of the $z(t)$ plots at 23 and $80^{\circ} \mathrm{C}$ is presented. The inset in Figure $6 \mathrm{~d}$ shows that these plots begin to differ at about $20 \mathrm{~ms}$. In the time domain $t>750 \mathrm{~ms}$, the evaporation effect on the water behavior becomes very significant, resulting in the equilibrium and then in receding stages of water dynamics indicated in Figure 6a. Snapshots $\mathrm{f} 1$ and $\mathrm{f} 2$ show the water film in the beginning $(t=1185 \mathrm{~ms})$ and end $(t=1385 \mathrm{~ms})$ of the equilibrium regime. Figure 6e and Snapshots e1-e3 obtained by the side-view camera show the water film profile dynamics. The temperature effect on the $h(t)$ dependence at $z=4 \mathrm{~mm}$ (location of the maximum water film thickness) is demonstrated in Figure 6e, where we also included the $h(t)$ dependences at other studied temperatures. These data show that at $t=780 \mathrm{~ms}$, the water film thickness decreases from 142 to $68 \mu \mathrm{m}$ as the temperature rises from 23 to $80^{\circ} \mathrm{C}$. The overall plot of spreading and receding velocities as functions of time is presented in Figure 6f, where the time domains of the spreading, 
equilibrium (see the inset i1), and receding regimes are also shown. At $t>1385 \mathrm{~ms}$ (see the inset i1), the water film front begins to recede with an increasing velocity, achieving an extremely high value of $27 \mathrm{~mm} / \mathrm{s}$ at $4185-4285 \mathrm{~ms}$ (see the inset i2). The sample surface becomes completely dry at $4285 \mathrm{~ms}$. Snapshots $\mathrm{f} 3-\mathrm{f} 5$ demonstrate the evaporating water film behavior in the receding regime. Snapshot $\mathrm{f} 5$ shows that the water film evaporation terminates at $z \approx 4 \mathrm{~mm}$, i.e., at the same location as at $60^{\circ} \mathrm{C}$ (see snapshot $\mathrm{f} 5 \mathrm{in}$ Figure $5 \mathrm{f}$ ).

The contact angle, $\theta_{\mathrm{CA}}$, is an important parameter in the capillary flow [106]. Therefore, we measured $\theta_{\mathrm{CA}}$ as a function of temperature for both untreated and treated surfaces. The obtained results are presented in Figure 7a. It is seen that in a temperature range between 23 and $80^{\circ}$, the contact angle of the untreated surface increases from 49 to $53.5^{\circ}$. The treated surface exhibits $\theta_{\mathrm{CA}} \approx 0^{\circ}$ in the entire studied temperature range, demonstrating stable super-hydrophilic properties with the variation in temperature. As compared with other reported micropillars' structures [107-109], our structure provides a better capillary performance. For example, a titanium micropillar array reported in Reference [107] demonstrates water spreading distance of about $5 \mathrm{~mm}$ within $100 \mathrm{~ms}$ for a water drop supply at the sample edge, whereas our structure transports water for the distance of about $11 \mathrm{~mm}$ (see Figure 3b).

A critical problem in creating capillary metallic surfaces is a quick degradation of their capillary performance caused by adsorption of hydrophobic hydrocarbons from the ambient air $[45,57,58]$. In our work, the superwicking functionality degradation over time was assessed by measuring the contact angle, $\theta_{\mathrm{CA}}$, of a deposited water drop using the OSA 200 system in video recording mode at a speed of $40 \mathrm{fps}$, allowing to measure the contact angle as a function of time after the drop deposition on the laser-structured surface. This test over a time period of about 7 months shows that the water static contact angle remains to be close to zero. During this period, the sample used in our experiments was subjected to multiple heating/cooling cycles, multiple wetting/drying cycles, and long exposure to Lab air containing hydrocarbons due to the presence of a large number plastic items in the Lab. The results of the test on contact angle dynamics performed immediately after laser processing and 7 months later are shown Figure $7 \mathrm{~b}$. It is seen that immediately after laser processing, the contact angle of a water drop deposited on the sample becomes close to zero within about $200 \mathrm{~ms}$, while 7 months later, this time is about $600 \mathrm{~ms}$, indicating some degradation of the wicking action. Despite this degradation, our sample retains its super-hydrophilic/wicking properties $\left(\theta_{\mathrm{CA}} \approx 0^{\circ}\right)$, in contrast to other laser-treated metals, which become superhydrophobic $\left(\theta_{\mathrm{CA}}>150^{\circ}\right)$ in $2-3$ months $[45,56,58]$. Taking into account that the number of wicking metallic materials with surface capillarity is currently very limited, the creation of both long-lasting and efficient wicking surface in our work is a significant result for further advancing important technological areas mentioned in the Introduction Section. An important feature of laser processing technologies is that modern industrial laser systems with a high pulse repetition rate (up to MHz-range) provide a laser nano/microstructuring speed up to about $1 \mathrm{~m}^{2} \mathrm{~s}^{-1}$, allowing mass production [55]. 

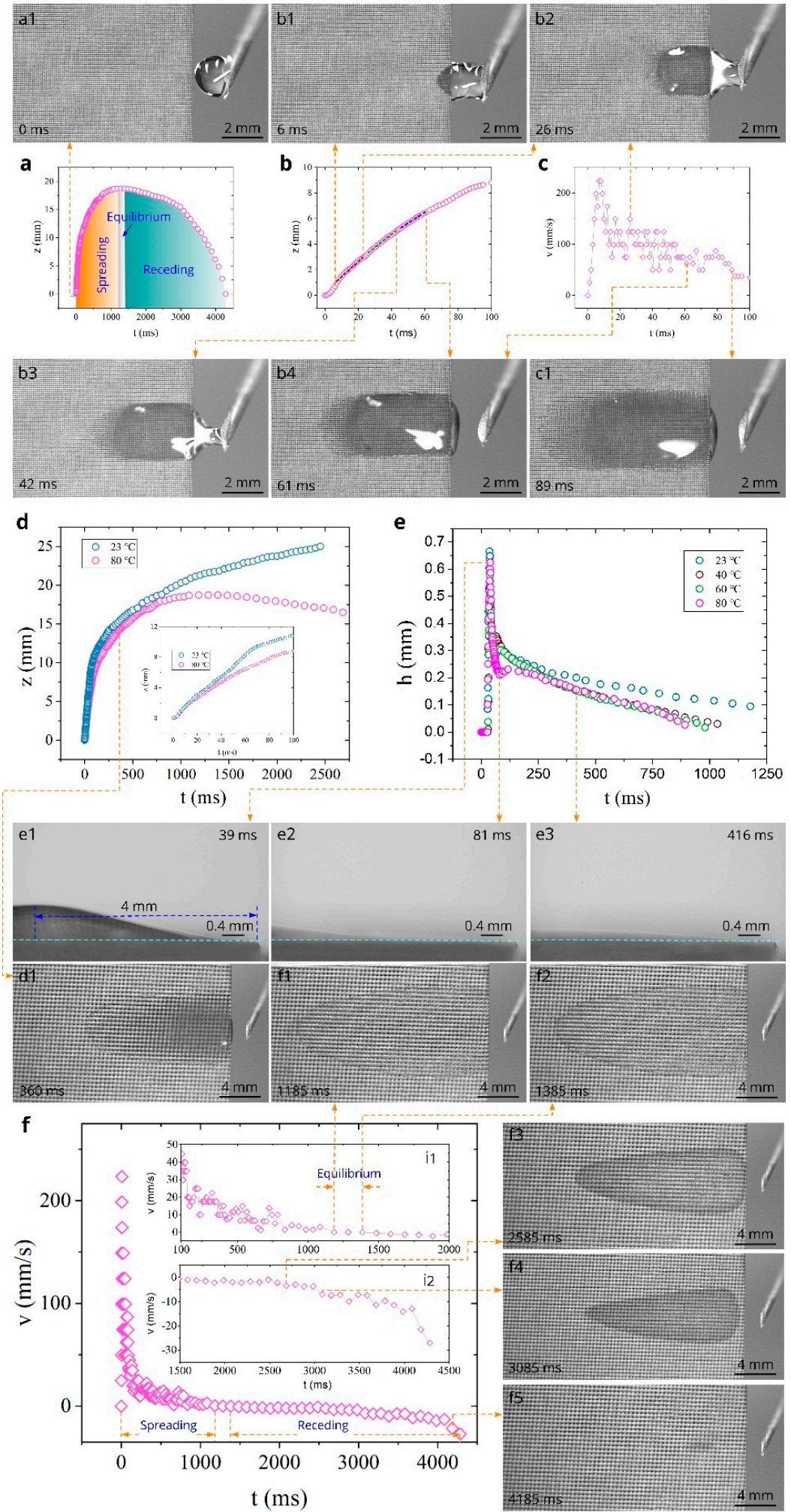

Figure 6. The $z(t), v(t)$, and $h(t)$ dependences at $80{ }^{\circ} \mathrm{C}$ and snapshots of water behaviors in spreading and receding regimes (experiment was performed 77 days after laser processing of the sample). (a) The overall plot of the spreading distance as a function of time. (b) Detailed $z(t)$ plot in the time domain between 0 and $100 \mathrm{~ms}$. The dashed lines show three $z \propto t$ substages. (c) Detailed plot of the spreading velocity as a function of time between 0 and $100 \mathrm{~ms}$. (d) The comparison of $z(t)$ dependences at 23 and $80{ }^{\circ} \mathrm{C}$. (e) The comparison of $h(t)$ dependences at the studied temperatures. (f) The overall plot of spreading and receding velocities as a function of time. 

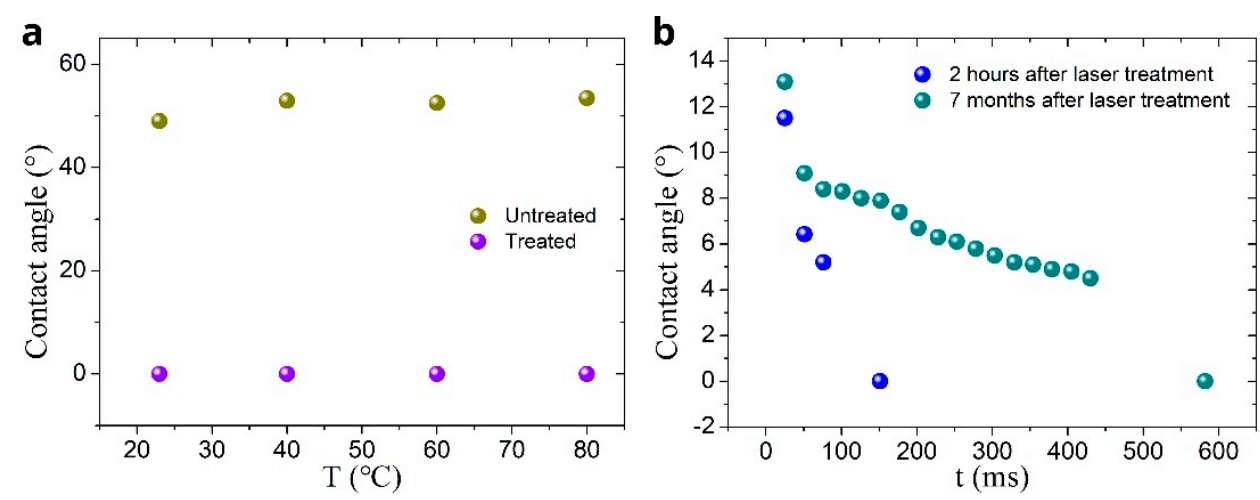

Figure 7. (a) Contact angle of a $2 \mu \mathrm{L}$ water drop on untreated and treated sample surfaces as a function of temperature. (b) Contact angle dynamics of a $2 \mu \mathrm{L}$ water drop on the treated sample measured immediately after laser processing and 7 months later.

\section{Conclusions}

In this work, we fabricated an array of periodic micropillars/microholes on a surface of a Ti-6Al-4V alloy plate, using a femtosecond laser nano/microstructuring technique. For enhancing capillary action, the surface of micropillars/microholes was additionally structured with both laser-induced periodic surface structures and fine random nano/microstructures. The created hierarchical capillary surface structure exhibited an extremely good capillary functionality in the temperature range between 23 and $80^{\circ} \mathrm{C}$. After the acceleration stage, the maximum water flow velocity in the inertial regime was found to be very high, achieving about $250 \mathrm{~mm} / \mathrm{s}$. The strong capillary action provides fast water spreading for a long distance (up to $5.6-7.2 \mathrm{~mm}$ ) even in the inertial flow regime $(0<t<50 \mathrm{~ms})$ at all studied temperatures. In a later stage of capillary flow, water quickly spread and formed a thin film over a large surface area, providing conditions for fast evaporation needed in applications based on liquid-vapor phase change. An important feature of the created material is a very slow degradation of its wicking functionality with time. The long-lasting wicking functionality along with a wide operational temperature range make the created texture suitable for a variety of practical applications, where the choice of materials is currently very limited, such as cooling high-heat flux electronics, thermal and fluid management in aerospace systems [5-7], cooling data centers [1,2], heat dissipation in power batteries and electronics of hybrid vehicles $[15,110,111]$, and M-cycle applications, including air-conditioning [21-25], waste heat recovery [10-12], water desalination/purification [8,9,112-114], and cooling towers [115]. Potential significant energy savings in air-conditioning of buildings [59] and cooling data centers [60] due to application of the material created here can contribute to mitigation of global warming.

Author Contributions: Conceptualization, A.Y.V. and R.F.; Preparation of Samples, R.F., Z.L. and X.Z. (Xianhang Zhang); Video Recording, X.Z. (Xiaohui Zhu), Z.H. and Z.P.; Data Analysis, Z.L., H.Z., J.L. and C.Y.; Funding Acquisition, R.F., W.Y. and Y.H.; Writing-original draft preparation, A.Y.V. and R.F.; Writing-review and editing, A.Y.V., R.F., Z.L., J.Z. and V.S.M. All authors have read and agreed to the published version of the manuscript.

Funding: This research was funded by National Development and Reform Commission (D61012018002), by Chongqing Basic and Frontier Research Project (cstc2018jcyjAX0209), and by the Technology Innovation and Application Demonstration key Project of Chongqing Municipality under Grant (cstc2018jszX-cyzdX0137).

Data Availability Statement: Data are contained within the article.

Conflicts of Interest: The authors declare no conflict of interest. 


\section{References}

1. Nadjahi, C.; Louahlia, H.; Lemasson, S. A review of thermal management and innovative cooling strategies for data center. Sustain. Comput. Inform. 2018, 19, 14-28. [CrossRef]

2. Han, Z.W.; Sun, X.Q.; Wei, H.T.; Ji, Q.; Xue, D. Energy saving analysis of evaporative cooling composite air conditioning system for data centers. Appl. Therm. Eng. 2021, 186, 116506. [CrossRef]

3. Izadi, A.; Siavashi, M.; Rasam, H.; Xiong, Q.G. MHD enhanced nanofluid mediated heat transfer in porous metal for CPU cooling. Appl. Therm. Eng. 2019, 168, 114843. [CrossRef]

4. Chernysheva, M.A.; Yushakova, S.I.; Maydanik, Y.F. Copper-water loop heat pipes for energy-efficient cooling systems of supercomputers. Energy 2014, 69, 534-542. [CrossRef]

5. Zhang, H.X.; Li, G.G.; Chen, L.; Man, G.L.; Miao, J.Y.; Ren, X.Z.; He, J.; Huo, Y.H. Development of flat-plate loop heat pipes for spacecraft thermal control. Microgravity Sci. Technol. 2019, 31, 435-443. [CrossRef]

6. Shukla, K.N. Heat pipe for aerospace applications-An overview. J. Electron. Cool. Therm. Control. 2015, 5, 1-14. [CrossRef]

7. Ku, J.T.; Ottenstein, L.; Douglas, D.; Hoang, T. Technology overview of a multi-evaporator miniature loop heat pipe for spacecraft applications. J. Spacecr. Rocket. 2012, 49, 999-1007. [CrossRef]

8. Zhang, X.T.; Liu, Y.X.; Wen, X.Y.; Li, C.Z.; Hu, X.J. Low-grade waste heat driven desalination with an open loop heat pipe. Energy 2018, 163, 221-228. [CrossRef]

9. Tariq, R.; Sheikh, N.A.; Xamán, J.; Bassam, A. An innovative air saturator for humidification-dehumidification desalination application. Appl. Energy 2018, 228, 789-807. [CrossRef]

10. Singh, S.C.; Elkabbash, M.; Li, Z.L.; Li, X.H.; Regmi, B.; Madsen, M.; Jalil, S.A.; Zhan, Z.B.; Zhang, J.H.; Guo, C.L. Solar-trackable super-wicking black metal panel for photothermal water sanitation. Nat. Sustain. 2020, 3, 938-946. [CrossRef]

11. Aono, Y.; Watanabe, N.; Ueno, A.; Nagano, H. Development of a loop heat pipe with kW-class heat transport capability. Appl. Therm. Eng. 2021, 183, 116169. [CrossRef]

12. Ouyang, T.C.; Su, Z.X.; Yang, R.; Li, C.Z.; Huang, H.Z.; Wei, Q.F. A framework for evaluating and optimizing the cascade utilization of medium-low grade waste heat in marine dual-fuel engines. J. Clean. Prod. 2020, 276, 123289. [CrossRef]

13. Brough, D.; Ramos, J.; Delpech, B.; Jouhara, H. Development and validation of a TRNSYS type to simulate heat pipe heat exchangers in transient applications of waste heat recovery. Int. J. Thermofluids 2021, 9, 100056. [CrossRef]

14. Jalil, S.A.; Elkabbash, M.; Li, Z.H.; Zhang, J.H.; Singh, S.; Zhan, Z.B.; Guo, C.L. Multipronged heat-exchanger based on femtosecond laser-nano/microstructured aluminum for thermoelectric heat scavengers. Nano Energy 2020, 75, 104987. [CrossRef] [PubMed]

15. Fang, Y.D.; Ye, F.; Zhu, Y.; Li, K.; Shen, J.L.; Su, L. Experimental investigation on system performances and transient response of a pumped two-phase battery cooling system using R1233zd. Energy Rep. 2020, 6, 238-247. [CrossRef]

16. Liao, Z.R.; Xu, C.; Ren, Y.X.; Gao, F.; Ju, X.; Du, X.Z. Thermal analysis of a conceptual loop heat pipe for solar central receivers. Energy 2018, 158, 709-718. [CrossRef]

17. Shafieian, A.; Khiadani, M.; Nosrati, A. Strategies to improve the thermal performance of heat pipe solar collectors in solar systems: A review. Energy Convers. Manag. 2019, 183, 307-331. [CrossRef]

18. Erickson, D.; Sinton, D.; Psaltis, D. Optofluidics for energy applications. Nat. Photonics 2011, 5, 583-590. [CrossRef]

19. Li, N.B.; Yang, D.J.; Shao, Y.; Liu, Y.T.; Tang, J.B.; Yang, L.P.; Sun, T.Y.; Zhou, W.J.; Liu, H.; Xue, G.B. Nanostructured black aluminum prepared by laser direct writing as a high-performance plasmonic absorber for photothermal/electric conversion. ACS Appl. Mater. Interfaces 2021, 13, 4305-4315. [CrossRef]

20. Su, Q.; Chang, S.N.; Zhao, Y.Y.; Zheng, H.K.; Dang, C.B. A review of loop heat pipes for aircraft anti-icing applications. Appl. Therm. Eng. 2018, 130, 528-540. [CrossRef]

21. Mahmood, M.H.; Sultan, M.; Miyazaki, T.; Koyama, S.; Maisotsenko, V.S. Overview of the Maisotsenko cycle-A way towards dew point evaporative cooling. Renew. Sustain. Energy Rev. 2016, 66, 537-555. [CrossRef]

22. Dizaji, H.S.; Hu, E.J.; Chen, L.; Pourhedayat, S. Comprehensive exergetic study of regenerative Maisotsenko air cooler; formulation and sensitivity analysis. Appl. Therm. Eng. 2019, 152, 455-467. [CrossRef]

23. Katramiz, E.; Al Jebaei, H.; Alotaibi, S.; Chakroun, W.; Ghaddar, N.; Ghali, K. Sustainable cooling system for Kuwait hot climate combining diurnal radiative cooling and indirect evaporative cooling system. Energy 2020, 213, 119045. [CrossRef]

24. Duan, Z.Y.; Zhao, X.D.; Zhan, C.H.; Dong, X.L.; Chen, H.B. Energy saving potential of a counter-flow regenerative evaporative cooler for various climates of China: Experiment-based evaluation. Energy Build. 2017, 148, 199-210. [CrossRef]

25. Zanchini, E.; Naldi, C. Energy saving obtainable by applying a commercially available M-cycle evaporative cooling system to the air conditioning of an office building in North Italy. Energy 2019, 179, 975-988. [CrossRef]

26. Duan, Z.Y.; Zhan, C.H.; Zhang, X.X.; Mustafa, M.; Zhao, X.D.; Alimohammadisagvand, B.; Hasan, A. Indirect evaporative cooling: Past, present and future potentials. Renew. Sustain. Energy Rev. 2012, 16, 6823-6850. [CrossRef]

27. Caliskan, H.; Hepbasli, A.; Dincer, I.; Maisotsenko, V. Thermodynamic performance assessment of a novel air cooling cycle: Maisotsenko cycle. Int. J. Refrig. 2011, 34, 980-990. [CrossRef]

28. Anisimov, S.; Pandelidis, D. Numerical study of the Maisotsenko cycle heat and mass exchanger. Int. J. Heat Mass Transf. 2014, 75, 75-96. [CrossRef]

29. Xu, P.; Ma, X.L.; Zhao, X.D.; Xiong, Y.X.; Sun, Y.B. Feasibility analysis for a novel dew point air cooler applied in warm and humid climate: A case study in Beijing. Energy Procedia 2019, 158, 2126-2131. [CrossRef] 
30. Li, H.; Liu, Z.C.; Chen, B.B.; Liu, W.; Li, C.; Yang, J.G. Development of biporous wicks for flat-plate loop heat pipe. Exp. Therm. Fluid Sci. 2012, 37, 91-97. [CrossRef]

31. Guo, H.; Ji, X.B.; Xu, J.L. Enhancement of loop heat pipe heat transfer performance with superhydrophilic porous wick. Int. J. Therm. Sci. 2020, 156, 106466. [CrossRef]

32. Zhang, Z.K.; Zhao, R.Z.; Liu, Z.C.; Liu, W. Application of biporous wick in flat-plate loop heat pipe with long heat transfer distance. Appl. Therm. Eng. 2021, 184, 116283. [CrossRef]

33. Vorobyev, A.Y.; Guo, C.L. Metal pumps liquid uphill. Appl. Phys. Lett. 2009, 94, 224102. [CrossRef]

34. Vorobyev, A.Y.; Guo, C.L. Direct femtosecond laser surface nano/microstructuring and its applications. Laser Photonics Rev. 2013, 7,385-407. [CrossRef]

35. Zhang, C.Y.; Cheng, L.; Tan, B.; Chen, Z.F.; Zhang, W.; Liu, Z.L.; Peng, J. Directional liquid spreading on laser textured aluminum surface. Microsyst. Technol. 2020, 26, 2767-2776. [CrossRef]

36. Fang, R.R.; Zhu, H.B.; Li, Z.K.; Zhu, X.H.; Zhang, X.H.; Huang, Z.Y.; Li, K.; Yan, W.S.; Huang, Y.; Maisotsenko, V.S.; et al. Temperature effect on capillary flow dynamics in 1D array of open nanotextured microchannels produced by femtosecond laser on silicon. Nanomaterials 2020, 796, 796. [CrossRef]

37. Xie, F.; Yang, J.J.; Ngo, C.V. The effect of femtosecond laser fluence and pitches between V-shaped microgrooves on the dynamics of capillary flow. Results Phys. 2020, 19, 103606. [CrossRef] [PubMed]

38. Fang, R.R.; Zhu, H.B.; Li, Z.K.; Yan, W.S.; Zhang, X.H.; Zhu, X.H.; Maisotsenko, V.S.; Vorobyev, A.Y. Capillary Nylon 6 polymer material produced by femtosecond laser processing. Opt. Express 2019, 27, 36066-36074. [CrossRef]

39. Kim, D.E.; Yu, D.I.; Park, S.C.; Kwak, H.J.; Ahn, H.S. Critical heat flux triggering mechanism on micro-structured surfaces: Coalesced bubble departure frequency and liquid furnishing capability. Int. J. Heat Mass Transf. 2015, 91, 1237-1247. [CrossRef]

40. Vaartstra, G.; Lu, Z.M.; Wang, E.N. Simultaneous prediction of dryout heat flux and local temperature for thin film evaporation in micropillar wicks. Int. J. Heat Mass Transf. 2019, 136, 170-177. [CrossRef]

41. Chu, K.H.; Joung, Y.S.; Enright, R.; Buie, C.R.; Wang, E.N. Hierarchically structured surfaces for boiling critical heat flux enhancement. Appl. Phys. Lett. 2013, 102, 151602. [CrossRef]

42. Dhillon, N.S.; Buongiorno, J.; Varanasi, K.K. Critical heat flux maxima during boiling crisis on textured surfaces. Nat. Commun. 2015, 6, 8247. [CrossRef] [PubMed]

43. Wei, M.Y.; He, B.; Liang, Q.; Somasundaram, S.; Tan, C.S.; Wang, E.N. Optimization and thermal characterization of uniform silicon micropillar based evaporators. Int. J. Heat Mass Transf. 2018, 127, 51-60. [CrossRef]

44. Zhu, Y.Y.; Antao, D.S.; Lu, Z.M.; Somasundaram, S.; Zhang, T.J.; Wang, E.N. Prediction and characterization of dry-out heat flux in micropillar wick structures. Langmuir 2016, 32, 1920-1927. [CrossRef] [PubMed]

45. Ahmmed, K.M.T.; Grambow, C.; Kietzig, A.M. Fabrication of micro/nano structures on metals by femtosecond laser micromachining. Micromachines 2014, 5, 1219-1253. [CrossRef]

46. Gamaly, E.G.; Rode, A.V. Physics of ultra-short laser interaction with matter: From phonon excitation to ultimate transformations. Prog. Quant. Electron. 2013, 37, 215-323. [CrossRef]

47. Shugaev, M.V.; Wu, C.P.; Armbruster, O.; Naghilou, A.; Brouwer, N.; Ivanov, D.S.; Derrien, T.J.Y.; Bulgakova, N.M.; Kautek, W.; Rethfeld, B.; et al. Fundamentals of ultrafast laser-material interaction. MRS Bull. 2016, 41, 960-968. [CrossRef]

48. Inogamov, N.A.; Zhakhovskii, V.V.; Ashitkov, S.I.; Petrov, Y.V.; Agranat, M.B.; Anisimov, S.I.; Nishihara, K.; Fortov, V.E. Nanospallation induced by an ultrashort laser pulse. J. Exp. Theor. Phys. 2008, 107, 1-19. [CrossRef]

49. Povarnitsyn, M.E.; Fokin, V.B.; Levashov, P.R.; Itina, T.E. Molecular dynamics simulation of subpicosecond double-pulse laser ablation of metals. Phys. Rev. B 2015, 92, 174104. [CrossRef]

50. Fang, R.R.; Vorobyev, A.Y.; Guo, C.L. Direct visualization of the complete evolution of femtosecond laser-induced surface structural dynamics of metals. Light Sci. Appl. 2017, 6, e16256. [CrossRef]

51. Vorobyev, A.Y.; Guo, C.L. Laser turns silicon superwicking. Opt. Express 2010, 18, 6455-6460. [CrossRef] [PubMed]

52. Zhu, Z.Q.; Li, G.Q.; Li, J.W.; Xie, H.; Hu, Y.L.; Chu, J.R.; Huang, W.H. Self-driven flow in surface grooves fabricated by femtosecond laser. Surf. Coat. Technol. 2014, 242, 246-250. [CrossRef]

53. Vorobyev, A.Y.; Guo, C.L. Superwicking glass produced by femtosecond laser. J. Appl. Phys. 2010, 108, 123512. [CrossRef]

54. Yin, K.; Duan, J.A.; Sun, X.Y.; Wang, C.; Luo, Z. Formation of superwetting surface with line-patterned nanostructure on sapphire induced by femtosecond laser. Appl. Phys. A 2015, 119, 69-74. [CrossRef]

55. Bonse, J.; Gräf, S. Maxwell meets Marangoni-A review of theories on laser-induced periodic surface structures. Laser Photonics Rev. 2020, 14, 2000215. [CrossRef]

56. Huerta-Murillo, D.; Garcia-Giron, A.; Romano, J.M.; Cardoso, J.T.; Cordovilla, F.; Walker, M.; Dimov, S.S.; Ocana, J.L. Wettability modification of laser-fabricated hierarchical surface structures in Ti-6Al-4V titanium alloy. Appl. Surf. Sci. 2019, 463, 838-846. [CrossRef]

57. Drelich, J.; Chibowski, E. Superhydrophilic and superwetting surfaces: Definition and mechanisms of control. Langmuir 2010, 26, 18621-18623. [CrossRef]

58. Vorobyev, A.Y.; Guo, C.L. Multifunctional surfaces produced by femtosecond laser. J. Appl. Phys. 2015, 117, 033103. [CrossRef]

59. Amer, O.; Boukhanouf, R.; Ibrahim, H.G. A review of evaporative cooling technologies. Int. J. Environ. Sci. Dev. 2015, 6, 111-117. [CrossRef] 
60. NSIDC Data Center: Energy Reduction Strategies. United States: U.S. Department of Energy, Energy Efficiency \& Renewable Energy, Federal Energy Management Program (FEMP), Report No. DOE/GO-102012-3509. 2012. Available online: https: / / www.energy.gov/sites/prod/files/2013/10/f3/nsidc_dcstrategies.pdf (accessed on 31 March 2021).

61. David, S.; Sefiane, K.; Tadrist, L. Experimental investigation of the effect of thermal properties of the substrate in the wetting and evaporation of sessile drops. Colloids Surf. A 2007, 298, 108-114. [CrossRef]

62. Chandramohan, A.; Dash, S.; Weibel, J.A.; Chen, X.M.; Garimella, S.V. Marangoni convection in evaporating organic liquid droplets on a nonwetting substrate. Langmuir 2016, 32, 4729-4735. [CrossRef] [PubMed]

63. Vorobyev, A.Y.; Makin, V.S.; Guo, C.L. Periodic ordering of random surface nanostructures induced by femtosecond laser pulses on metals. J. Appl. Phys. 2007, 101, 034903. [CrossRef]

64. Makin, V.S.; Makin, R.S.; Vorobyev, A.Y.; Guo, C.L. Dissipative nanostructures and Feigenbaum's universality in the "Metal-highpower ultrashort-pulsed polarized radiation" nonequilibrium nonlinear dynamical system. Tech. Phys. Lett. 2008, 34, 387-390. [CrossRef]

65. Hwang, T.Y.; Guo, C.L. Angular effects of nanostructure-covered femtosecond laser induced periodic surface structures on metals. J. Appl. Phys. 2010, 108, 073523. [CrossRef]

66. Ionin, A.A.; Kudryashov, S.I.; Rudenko, A.A.; Seleznev, L.V.; Sinitsyn, D.V.; Makarov, S.V. Nonlinear optical feedback for nanoand micropatterning of silicon surface under femtosecond laser irradiation. Opt. Mater. Express 2017, 7, 2793-2807. [CrossRef]

67. Vorobyev, A.Y.; Guo, C.L. Nanochemical effects in femtosecond laser ablation of metals. Appl. Phys. Lett. 2013, $102,074107$. [CrossRef]

68. Kolobov, Y.R.; Zhidkov, M.V.; Golosov, E.V.; Vershinina, T.N.; Kudryashov, S.I.; Makarov, S.V.; Ionin, A.A.; Ligachev, A.E. Phase composition and structure of femtosecond laser-produced oxide layer on VT6 alloy surface. Laser Phys. Lett. 2016, 13, 076103. [CrossRef]

69. Ionin, A.A.; Kudryashov, S.I.; Makarov, S.V.; Saltuganov, P.N.; Seleznev, L.V.; Sinitsyn, D.V.; Golosov, E.V.; Goryainov, A.A.; Kolobov, Y.R.; Kornieieva, K.A.; et al. Femtosecond laser modification of titanium surfaces: Direct imprinting of hydroxylapatite nanopowder and wettability tuning via surface microstructuring. Laser Phys. Lett. 2013, 10, 045605. [CrossRef]

70. Stange, M.; Dreyer, M.E.; Rath, H.J. Capillary driven flow in circular cylindrical tubes. Phys. Fluids 2003, 15, 2587-2601. [CrossRef]

71. Huang, W.F.; Liu, Q.S.; Li, Y. Capillary filling flows inside patterned-surface microchannels. Chem. Eng. Technol. 2006, 29, 716-723. [CrossRef]

72. Das, S.; Waghmare, P.R.; Mitra, S.K. Early regimes of capillary filling. Phys. Rev. E 2012, 86, 067301. [CrossRef] [PubMed]

73. Quere, D. Inertial capillarity. Europhys. Lett. 1997, 39, 533-538. [CrossRef]

74. Siebold, A.; Nardin, M.; Schultz, J.; Walliser, A.; Oppliger, M. Effect of dynamic contact angle on capillary rise phenomena. Colloids Surf. A 2000, 161, 81-87. [CrossRef]

75. Andrukh, T.; Monaenkova, D.; Rubin, B.; Lee, W.K.; Kornev, K.G. Meniscus formation in a capillary and the role of contact line friction. Soft Matter 2014, 10, 609-615. [CrossRef]

76. Fries, N.; Dreyer, M. The transition from inertial to viscous flow in capillary rise. J. Colloid Interface Sci. 2008, 327, 125-128. [CrossRef] [PubMed]

77. Washburn, E.W. The dynamics of capillary flow. Phys. Rev. 1921, 17, 273-283. [CrossRef]

78. Deng, D.X.; Tang, Y.; Zeng, J.; Yang, S.; Shao, H.R. Characterization of capillary rise dynamics in parallel micro V-grooves. Int. J. Heat Mass Transf. 2014, 77, 311-320. [CrossRef]

79. O'Loughlin, M.; Wilk, K.; Priest, C.; Ralston, J.; Popescu, M.N. Capillary rise dynamics of aqueous glycerol solutions in glass capillaries: A critical examination of the Washburn equation. J. Colloid Interface Sci. 2013, 411, 257-264. [CrossRef] [PubMed]

80. Courbin, L.; Denieul, E.; Dressaire, E.; Roper, M.; Ajdari, A.; Stone, H.A. Imbibition by polygonal spreading on microdecorated surfaces. Nat. Mater. 2007, 6, 661-664. [CrossRef]

81. Xing, H.T.; Cheng, J.; Zhou, C.L. Effect of gradient wettability on capillary imbibition in open semicircular copper channel. Phys. Fluids 2020, 32, 112004. [CrossRef]

82. Fu, R.; Hu, X.G.; Zhang, H.J.; Yan, Y.Y.; Zhou, W.B.; Wang, J.H. Investigation of the influence of $\mathrm{Fe}_{3} \mathrm{O}_{4}$-water nanofluids on capillary performance in microgrooves wick. Appl. Therm. Eng. 2021, 182, 115899. [CrossRef]

83. Abdulshaheed, A.A.; Wang, P.T.; Huang, G.H.; Li, C. High performance copper-water heat pipes with nanoengineered evaporator sections. Int. J. Heat Mass Transf. 2019, 133, 474-486. [CrossRef]

84. Zhang, S.W.; Lin, L.; Chen, G.; Tang, H.; Zeng, J.; Yuan, W.; Tang, Y. Experimental study on the capillary performance of aluminum micro-grooved wicks with reentrant cavity array. Int. J. Heat Mass Transf. 2019, 139, 917-927. [CrossRef]

85. Siddique, J.I.; Anderson, D.M.; Bondarev, A. Capillary rise of a liquid into a deformable porous material. Phys. Fluids 2009, 21, 013106. [CrossRef]

86. Tang, J.C.; Hu, X.G. Evaluation of capillary wetting performance of micro-nano hybrid structures for open microgrooves heat sink. Exp. Therm. Fluid Sci. 2020, 112, 109948. [CrossRef]

87. Kim, S.J.; Moon, M.W.; Lee, K.R.; Lee, D.Y.; Chang, Y.S.; Kim, H.Y. Liquid spreading on superhydrophilic micropillar arrays. J. Fluid Mech. 2011, 680, 477-487. [CrossRef]

88. Tian, J.F.; Kannangara, D.; Li, X.; Shen, W. Capillary driven low-cost V-groove microfluidic device with high sample transport efficiency. Lab. Chip 2010, 10, 2258-2264. [CrossRef] [PubMed]

89. Bico, J.; Tordeux, C.; Quere, D. Rough wetting. Europhys. Lett. 2001, 55, 214-220. [CrossRef] 
90. Rye, R.R.; Mann, J.A.; Yost, F.G. The flow of liquids in surface grooves. Langmuir 1996, 12, 555-565. [CrossRef]

91. Romero, L.A.; Yost, F.G. Flow in an open channel capillary. J. Fluid Mech. 1996, 322, 109-129. [CrossRef]

92. Yang, M.; Cao, B.Y.; Wang, W.; Yun, H.M.; Chen, B.M. Experimental study on capillary filling in nanochannels. Chem. Phys. Lett. 2016, 662, 137-140. [CrossRef]

93. Haneveld, J.; Tas, N.R.; Brunets, N.; Jansen, H.V.; Elwenspoek, M. Capillary filling of sub-10 nm nanochannels. J. Appl. Phys. 2008, 104, 014309. [CrossRef]

94. Fisher, L.R.; Lark, P.D. An experimental study of the Washburn equation for liquid flow in very fine capillaries. J. Colloid Interface Sci. 1979, 69, 486-492. [CrossRef]

95. Dimitrov, D.I.; Milchev, A.; Binder, K. Capillary rise in nanopores: Molecular dynamics evidence for the Lucas-Washburn equation. Phys. Rev. Lett. 2007, 99, 054501. [CrossRef]

96. Bar-Cohen, A.; Geisler, K.J.L. Cooling the electronic brain. Mech. Eng. 2011, 133, 38-41. [CrossRef]

97. Ebadian, M.A.; Lin, C.X. A review of high-heat-flux heat removal technologies. J. Heat Transf. 2011, 133, 110801. [CrossRef]

98. Chen, L.G.; Shen, J.F.; Ge, Y.L.; Wu, Z.X.; Wang, W.H.; Zhu, F.L.; Feng, H.J. Power and efficiency optimization of open MaisotsenkoBrayton cycle and performance comparison with traditional open regenerated Brayton cycle. Energy Convers. Manag. 2020, 217, 113001. [CrossRef]

99. Zhu, F.L.; Chen, L.G.; Wang, W.H. Thermodynamic analysis of an irreversible Maisotsenko reciprocating Brayton cycle. Entropy 2018, 20, 167. [CrossRef]

100. Zhu, G.Y.; Chow, T.T.; Fong, K.F.; Lee, C.K. Investigation on humidified gas turbine cycles with Maisotsenko-cycle-based air saturator. Energy Procedia 2019, 158, 5195-5200. [CrossRef]

101. Saghafifar, M.; Gadalla, M. Analysis of Maisotsenko open gas turbine power cycle with a detailed air saturator model. Appl. Energy 2015, 149, 338-353. [CrossRef]

102. Abgrall, P.; Gue, A.M. Lab-on-chip technologies: Making a microfluidic network and coupling it into a complete microsystem-A review. J. Micromech. Microeng. 2007, 17, R15-R49. [CrossRef]

103. Marmur, A. Penetration of a small drop into a capillary. J. Colloid Interface Sci. 1988, 122, 209-219. [CrossRef]

104. Radiom, M.; Chan, W.K.; Yang, C. A study of capillary flow from a pendant droplet. Microfluid. Nanofluid. $2009,7,697-707$. [CrossRef]

105. Lade, R.K.; Hippchen, E.J.; Macosko, C.W.; Francis, L.F. Dynamics of capillary-driven flow in 3D printed open microchannels. Langmuir 2017, 33, 2949-2964. [CrossRef] [PubMed]

106. Alhosani, M.H.; Zhang, T.J. Dynamics of microscale liquid propagation in micropillar arrays. Langmuir 2017, 33, 6620-6629. [CrossRef] [PubMed]

107. Ding, C.S.; Meinhart, C.D.; MacDonald, N.C. Surface modifications of bulk micromachined titanium pillar arrays: A wick material for thin flat heat pipes. In Proceedings of the ASME 2009 Second International Conference on Micro/Nanoscale Heat and Mass Transfer, Shanghai, China, 18-21 December 2009; pp. 415-419. [CrossRef]

108. Srivastava, N.; Din, C.S.; Judson, A.; MacDonald, N.C.; Meinhart, C.D. A unified scaling model for flow through a lattice of microfabricated posts. Lab. Chip 2010, 10, 1148-1152. [CrossRef]

109. Xiao, R.; Wang, E.N. Microscale liquid dynamics and the effect on macroscale propagation in pillar arrays. Langmuir 2011, 27, 10360-10364. [CrossRef]

110. Rao, Z.H.; Wang, S.F. A review of power battery thermal energy management. Renew. Sustain. Energy Rev. 2011, 15, 4554-4571. [CrossRef]

111. Mudawar, I.; Bharathan, D.; Kelly, K.; Narumanchi, S. Two-phase spray cooling of hybrid vehicle electronics. IEEE Trans. Compon. Packag. Technol. 2009, 32, 501-512. [CrossRef]

112. Vaartstra, G.; Zhang, L.N.; Lu, Z.M.; Díaz-Marín, C.D.; Grossman, J.C.; Wang, E.N. Capillary-fed, thin film evaporation devices. J. Appl. Phys. 2020, 128, 130901. [CrossRef]

113. Wu, L.; Dong, Z.C.; Cai, Z.R.; Ganapathy, T.; Fang, N.X.; Li, C.X.; Yu, C.L.; Zhang, Y.; Song, Y.L. Highly efficient three-dimensional solar evaporator for high salinity desalination by localized crystallization. Nat. Commun. 2020, 11, 521. [CrossRef] [PubMed]

114. Menon, A.K.; Haechler, I.; Kaur, S.; Lubner, S.; Preasher, R.S. Enhanced solar evaporation using a photo-thermal umbrella for wastewater management. Nat. Sustain. 2020, 3, 144-151. [CrossRef]

115. Pandelidis, D. Numerical study and performance evaluation of the Maisotsenko cycle cooling tower. Energy Convers. Manag. 2020, 210, 112735. [CrossRef] 